\section{ON THE CONFLUENCES AND BIFURCATIONS OF CERTAIN THEORIES ${ }^{1}$}

A XIOMS, says Proclus, ${ }^{2}$ are common to all sciences, though each employs them in its peculiar subject-matter. A little further on ${ }^{3}$ he cites Aristotle ${ }^{4}$ as saying that one science is more certain than another, viz. that which emanates from more simple suppositions than that which uses more various principles; and that which tells the why, than that which tells only the simple existence of a thing; and that which is conversant about intelligibles, than that which touches and is employed about sensibles.

Proclus adds that, according to these definitions of certainty, arithmetic is more certain than geometry, since its principles excel by their simplicity. For the conception of unity has no reference to position in space, while that of a point involves such reference. In short, we may say that to count a number of objects is a simpler operation than to measure the distances between them.

All this, and much more, shows how early the notion of what is sometimes called a hierarchy of the sciences arose. Proclus's order of precedence would seem to be this, viz. logic, ${ }^{5}$ arithmetic, geometry, mechanics, optics, dioptrics, ${ }^{6}$ and so on; the progression being from the more to the less abstract, or from the abstract to the concrete.

Francis Bacon, mindful perhaps of Proclus, ${ }^{7}$ and duly appreciating the power of mathematics as an instrument ${ }^{8}$ and its value as a discipline, ${ }^{9}$ expressly takes the degree of abstractness of a science as the mark for its classification. He places mathematics, as the most abstract of sciences, ${ }^{10}$ at one end of the scale and "policy" at the other. He does not graduate the scale minutely, but it may be that, as in the case of the categories, ${ }^{11}$ he attached no great value to such details. Distinguishing philosophy from theology, logic, and mathematics, ${ }^{12}$ he assigns to it the axioms which are common to several sciences and the inquiry into essences, as quantity, similitude, diversity, possibility, and the rest. Science he divides between metaphysics, the science of the abstract and permanent, and physics, that of matter and its changes. ${ }^{13}$ Bacon, in one place, names the one universal science by the name of philosophy, while in another he treats philosophy and metaphysics as two distinct things. ${ }^{14} \mathrm{He}$ uses the word metaphysics in a sense different from that in which it was then ${ }^{15}$ received. Mathematics he places as a branch of metaphysics, and as having determined or determinate quantity for its subject. To the pure mathematics, he says, belong geometry and arithmetic; the one handling continuous, and the other discrete quantity. ${ }^{16}$ If he means continuous quantity so far as it is immovable, he agrees with the Pythagoreans. 17

Quantity, time, and space are placed by Aristotle among his categories, or are implied in them. With regard to space, he does not seem to have reached the Kantian view in any way, nor to be very clear in his meaning, though he apparently feels that to realize space we must have motion. His conception of time as one of the elements required for measuring motion, and his starting the problem as to whether we could have time without a mind to conceive, seem a more distinct approximation, though only an approximation, to Kant's view of time as merely a subjective condition of perception. ${ }^{18}$

I Presidential Address delivered by Sir James Cockle, F.R.S., to the London Mathematical Society, on November $8, x 888$

Proclus, "Commentaries on the First Book of Euclid's Elements" (Taylor's Translation, London, 1792), p. $9^{2}$.

3 Proclus, op. cit., p. 93 .

Taylor (ib. p. 93) supplies the reference to the first Analytics, t. 42.

5 Proclus, op. cit., p. 79. IItme ("Treatise," vol. i., London, r739, Book i. Part 3, p. 129. et vid. p. I28) says that geometry falls short of that perfect precision and certainty which are peculiar to arithmetic and algebra.

6 Proclus, of. cit., p. 93 ; ct vid. pp. 78,79 . I633), pp. 49,50

Bacon, op. cit., pp. I5I, I52; et wid. pp. rrg, 120

9 Bacon, op. cit., pp. I52, 205 , and $23 \mathrm{I}$.

10 Bacon, op. cit., p. $2 \mathrm{I} 8$; t t vid. pp. I50, I5

Ir Bacon, op. cit., pp. 130, r3r, I40, and $20 \mathrm{r}$; et vid. p. $16 \mathrm{r}$

i2 Bacon, os. cit., pp. 49, 50 ; et ride. pp. $130, \mathrm{r} 3 \mathrm{I}$, and 14 ?

13 Bacon, op, cit. p.

14 Bacon, op. cit., p. I41.

15 Bacon, op. cit., p. I 38 ; conf. pp. I46, I47.

16 Bacon, op. cit., pp. 550 , r $5 \mathrm{r}$.

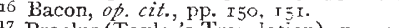

17 Proclus (Taylor's Translation), p. 74

For this summary of Aristotle's views I am indebted to Mr. Reginald $\mathrm{H}$. Roe, who referred me to Ueberweg's "Hist. of Phil.," p. r64. for a more elucidation, adding that in kitte and Preller's extracts, pp. 288 and 289 , will
Newton, in the Scholium to his definitions, distinguishes between absolute and relative time, the latter being time conceived in its relation to phenomena. Of absolute time (otherwise called duration) which has no relation to anything external, he says that it flows equably, and that its rate of flow and the order of its parts are immutable. In his "Fluxions" he uses the word time in a somewhat different sense, viz. as meaning the independent variable, characterized by an equable increase, fluxion, or flow. ${ }^{1}$ Sir W. Rowan Hamilton treated algebra as the science of pure time, but his doctrine is not entirely ${ }^{2}$ assented to by De Morgan, nor by Prof. Cayley, who indeed, in his Southport Address (p. 19), intimates dissent from it. Proclus does not connect arithmetic with time, and Prof. Cayley suggests (ib. p. 18) that, in any case, the notion of number or plurality is not more dependent on time than on space. By the logicians, time seems to be regarded as the more abstract of the pure intuitions. In fact, time is implied in memory and in thought itself, and Prof. Francis W. Newman observes that no man could get through a syllogism if he forgot the first premiss while dwell ing on the second. ${ }^{3}$ Moreover, he has recourse to the idea of time when he comes to discuss propositions, ${ }^{4}$ and Boole investigates the nature of the connection of his own secondary propositions with the idea of time. ${ }^{5}$ The ancient Indians had their cyclical periods, but not therefore necessarily any notion of a uniform curvature (so to say) of time.

Absolute space, says Newton, perpetually remains similar to itself and immovable ; and, further on in the Scholium, he adds that the order of its parts is immutable. In the preface to the "Principia" he had observed that the description of straight lines and circles, on which geometry is founded, belongs to mechanics, and he follows up this train of thought. But, whether he means to detach himself from Plato, I must leave others to say. It is said to be certain that he was familiar with Bacon's works ; that he uses the word axiom, not in Euclid's sense, but in Bacon's, thus giving the name of axioms to the laws of motion, which, of course are ascertained by the scrutiny of nature, and to those general experimental truths which form the groundwork of optics. ${ }^{6}$ Now Bacon says that, in his judgment, the senses are sufficient to certify and report truth, either immediately or by way of comparison. ${ }^{7}$ Moreover, he suggests that the rule Quce in eodem tertio conveniunt, et inter se conveniunt, a rule so potent in logic as that all syllogisms are built upon it, is taken from the mathematics. ${ }^{8}$ In seeking an origin for the more abstract in the less abstract, Bacon is not solitary. Thomas Stephens Davies suggested ${ }^{9}$ that the argument from superposition had its origin in mechanical considerations, and from the fitting together of material figures. Moreover, it is conceivable that some observant person among the ancient Egyptians, whose custom it was to stamp their bricks, noticing the resemblances of the miarks and the correspondence of the impresions with the impressing tool, may have been led to a recognition of the rule quoted by Bacon. The doctrine that there enters into geometry an element derived from the senses has, indeed, appeared in books designed for ordinary re aders. Thus, Prof. Newman, writing in $1836-38$, although in one part

be found all the important passages from Aristotle bearing on the question. As to the views of Boole, see his "Laws of Thought" (London, 1854), pp. I62 et seq.; see also p. 419. Boole treats of space at pp. 163,175 , and 418 and at p. I75 he quotes Aristotle's statements respecting the ex istence of space in three dimensions.

I Newton, "Fluxions," pp. 26 and $3^{8}$ of the small edition (London, 1737 ) This is a genuine work of Newton's. As to its bibliography, see Notes and

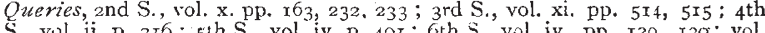

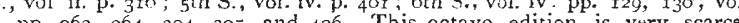
v. pp. $263,264,304,305$, and 426 . This . octavo edition is very scarcs. of the Royal Astronomical Siciety.

2 De Morgan, "On the Foundation of Algebra," Cambridge Transactions, vol. vil. pp. I $73-87$; see pp. I75, r 76 . The remarks of Prof. Cayley tions, vol. vil. pp. ${ }^{7} 73^{-8} 7$, see $\mathrm{pp}$. ${ }^{\mathrm{T} 75}, \mathrm{~T} 76$. The remarks of Prof. Cayley
on Whewell, at p. 18 of his Southport Address, are applicable to Rowan Hamilton.

3 Newman, "Lectures on Logic, or on the Science of Evidence," \&c. (Oxford, 1838 ), p. I5.

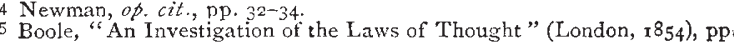
I62 et seq.

6 See the account of the "Novum Organon" in the "Library of Useful Knowledge," p. ro.

Bacon," Advancement of Learning" (cited supra), p. 193.

Bac sn, op. cit. p. 132.

'T. S. Davies, Geometrical N stes, Mechanics* Magazine, vol. liii. (I850) pp. $r \equiv 0,169,262,291,44^{2}$. Davies points out "the connection between parallels and similar triangles." He thinks that Aristotle's secession from the school of Plato arose from his enforcement of his own logical doctrines. Davies rejects the notion of a geometry built upon definitions alone without the assistance of axioms. 
of his "Logic" (p. 25), he says that in geometry no results are admitted by help of observation and testimony, but only by reasoning from the definition, yet he afterwards ( $p .55)$ states that, as space and its properties appear undeniably to be learned by sense, the argument seems to him to preponderate for naming geometry a mixed science, and believing that its propositions are real and not verbal truths. And Potts ${ }^{1}$ says that geometry seems to rest on the simplest inductions from experience and observation, and that its principles are founded on facts cognizable by the senses.

But it is to Reid ${ }^{2}$ that the idea of a more precise mathematical treatment of the subject is due, and his name ought to head the roll on which will be inscribed the names of Lobatschewsky, Riemann, and other investigators. Kant, indeed, disposes of such questions summarily, by saying that it follows from his premisses that the propositions of geometry are not the determinations of a mere creature of our feigning fancy, but that they necessarily hold of space, and consequently of all that may be met within it, because space is nothing else than the form of all the external phenomena, in which alone objects of sense can be given ("Prolegomena," ${ }^{3}$ p. 5I). He adds (pp. 5I and 53) that external phenomena must necessarily and precisely agree with the propositions of the geometer. Whether Kant's allusion to "superficial metaphysicians" points to the Pyrrhonists and Epicureans ${ }^{4}$ or to others, and, possibly, even to Reid, whom he had mentioned before (Preface, p. viii.), does not appear. Whatever opinions be formed of Kant's theory, or of the nature of space, his view is impressive. Confine that view to two dimensions, and suppose the surface of a sphere to be inhabited by a being destitute of any conception of a third dimension, and whose senses are unaffected by any point not situated or any motion not taking place on that surface. He could only estimate direction and position by the tangent to the path of the visual ray at the point where that path meets his visual organ, and would think that all objects were situate in one plane. His geometry would be Euclidian; for, if he could form a notion of the actual paths of rays, he would have a conception of the third dimension in space. ${ }^{5}$ Here Kant and Riemann would apparently be at issue ; for, if a more general conception of space is to be rendered special by actual measurements on the sphere, then, after an enlarged experience, the Euclidian conception would have to be expelled and replaced by some other. And all this would have to be done without praying in aid the excluded third dimension.

Aristotle ${ }^{6}$ notices that the nature of everything is best seen in its smallest portions, and Kant 7 remarks that there was a time when mathematicians, who were philosophers too, began to doubt, not the truth of their geometrical propositions as far as they regard space, but the objective validity and applicability of the conception itself, and of all its determinations, to nature; as they were apprehensive that a line in nature might consist of physical points, and that consequently true space in the object might consist of simple parts, though space as conceived by the geometer cannot so consist. Clifford ${ }^{8}$ would have given due weight to the doubts of the philosophical mathematicians. He even suggests that the properties of space may change with time. Now, a number may be a function of an angle; the very angle itself determines those numbers (ratios of lines) which we call sines anil cosines. But, says De Morgan, ${ }^{9}$ in every case but this it is impossible to conceive number a function of magnitude. It seems almost equally difficult to entertain Clifford's conjecture, which, nevertheless, measurements might verify. The sentence, Nam tempora et spatia sunt sui ipsorum et rerum omnium quasi Loca, in Newton's Scholium, though it may suggest that omnipresence does not involve extension in space, implies no functional relation between space and time. The words "then and

X Potts (Robert), "Euclid's Elements of Geometry," \&c. (Cambridge and London, 1845); Notes to Book i., p. 4r.

Thomas Reid. "An Inquiry into the Human Mind on the Prínciples of Common Sense" (1764). My pagings refer to the Calcutta Reprint of 1869 . Chap:er v1. treats (pp. 94-277) of Seeing; its Section vii. (pp. 120-24), of Geometry of Visibles. In Section viii (pp. $125^{-32}$ ), we have Some Queries concerning Visible Figure answered.

3 I cite from Richardson's Translation (London, 1819); and cannot now give the corresponding paging in that of Prof. Mahaffy.

Montucla, "Histoire" (2de édition, An. vii.), p. 2 r.

5 See Cayley, Southport Address, pp. II, I2.

6 See Bacin, "Advancement of Learning," p. I08.

7 Kant, "Prolegomena," p. 52.

8 William Kingdon Cliff rd, "Mathenatical Papers"

pp. $x l$. and $x l$ i. of the Introduction, by. H. J. S. Smith. Aggregation of Forces is a Consequence" (Camb. Trans., vol. x., part 2, pp. 294, 295, footnote). there," accompanying every material allegation in indictments, would suffice to show that the opinions of the world at large on certain characteristics of time and space ${ }^{1}$. were in accord with that of the philosophers. Indeed, their isolation, as forms of intuition, may no more be a peculiarity of Kant's system than is his distinction between analytical and synthetical judgments. This distinction was present to the mind of Bacon," as well as to that of Locke, whom Kant cites ("Prolegomena," p. 25), and who, elsewhere than in the place cited, adverts to the distinction. That which Locke had styled a trifling proposition, Kant called an analytical judgment ; and that which Locke ("Essay concerning Human Understanding," book iv., chap. viii., Sect. 8) styled a real truth, Kant would would have called a synthetical judgment. With Hume, too, Kant is in some respects in close relation. Hume ("Treatise," vol. i., book i., part 2, pp. 53-I24) treats specially of the ideas of space and time. Hume, again ("Inquiry," p. 17 ; Essay iv., p. 50), distinguishes between results attained by reasonings a priori and results arising entirely from experience ("Inquiry," p. I 7 ; Essay, p. 49). He seems to allow conception a sufficiently wide range, for he urges ("Inquiry," p. I3 ; Essay ii., pp. 26, 27) that, in one exceptional instance, there may be an idea not arising from a corresponding impression; viz. in the case when from the impressions of two distinct shades of a particular colour, a conception is formed of an intermediate shade of the same colour. He asserts ("Inquiry," p. I I8) that the only objects of the abstract sciences or of demonstration are quantity and number.

If, as Clifford ${ }^{3}$ seems to think, there are no sufficient grounds for maintaining that, if our space has curvature, it must be contained in a space of more dimensions and no curvature, one difficulty is apparently removed. The one-dimensioned time is something very different to space, from which the higherdimensioned entity might differ still more; and if a solid be treated as the shadow or projection in Euclid's space of, say, a four-dimensioned body, that part of the body which lies outside the shadow seems to have no quality analogous to impenetrability or inertia, nor indeed any quality which affects the senses or deranges the results of calculation. Prof. Cayley says (Southport Address, p. I I) that Riemann's idea reems to be that of modifying the notion of distance, not that of treating it as a locus in fourdimensional space. The suggestion (Cayley, $i b . p$. Io) of a rule changing its length by an alteration of temperature facilitates apprehension. Prof. von Helmholtz has 'considered the effect of the changes in sensible phenomena which a transition to a spherical or pseudo-spherical world, if such things be, would produce; and he has taken an independent view of the subject in other respects. ${ }^{4}$

De Morgan ${ }^{5}$ professed to have been puzzled to know on which side the meeting of parallels took place, or whether on both. He concludes that they never meet. This, however, does not shake, nor is it to be suppo-ed that he wished ${ }^{6}$ it to shake, the belief in modern methods, for he apparently admits that interpretation of forms may demand conclusions which can be reached by reasoning on infinity, if increase withont limit show approach. He observes that it is clearly conceived by the logicians that all division is reducible to simple dichotomy an? its repetitions, and that when the logician has once shown division, difference, he does not trouble himself with the difficulty of repetitions. De

I I should have been glad to have given Locke's and Kant's descriptions of space and time, and to have compared them with Newton's But I cannot printed in the Philosophical Magazine for June 1887, S. 5, vol. xxiii. pp. $473-89$.

3 Clifford, "The Universal Statements of Arithmetic" Nineteenth Century (1879, vol. v., pp. 513-22; vide p. 522).

A paper in Mind. by Prof. von Helmholtz, elicited a criticism from Prof. Land, which produced a reply; and with a brief note appended to a paper on another subject, by Prof. Land, the discussion closed. See Mind, vol. i.
pp. $30 \mathrm{I}-2 \mathrm{x}$; vol ii. pp. $3^{8}-46$; vol. iii. pp. $212-25$ and $55 x-55$; and vol. iv. pp. $59 \mathrm{x}-76$

5 De Morgan, “On Infinity," \&c. (Camb. 'Trans., vol. xi. Part I, $186{ }_{5}$ pp. 145-89; vid. pp. 173, 176. 180, 147). In connection with this paper, the comments of $\mathrm{Mr}$ W. S. B. Woolhouse in the Educational. Times (Reprint, vol. vi. pp. 49-52) should be considered. And in connection with a paragraph at pp. 16I, $\mathrm{I}^{r} 2$, of De Morgan's paper, the leading paragraph of p. 424 of a previous paper of $h \mathrm{~s}$, "On the Theory of Errors of Ohservation" (C. $\mathrm{T}$, , v1.1. x. Pt. 2, 1862), should be read. In the last-mentioned passage he distinguishes between the zero and the indivisible of probability. $H$ amilton of Edinburgh, foll,wing earlier authorities, expressly restricts the application of logic to finite things. But it does not therefore follow that logicians in general turn a deaf ear to all reasoning upon infinities and infinitesimals, and that they reject results stamped with authority and universally accepted.

6 This sufficiently appears from a statement at p. 15 of his paper, "On the Rost," \&c. (Camb. Trans., vol. xi. Pt. 2). 
Morgan's remark is easily verified by turning to Potts's Note on Euc. i. Io (p. 49). Turningragain to Boole ("L. of T.," p. 9I), it would seem that the logician does not completely detach himself from the notion of infinity : he has to interpret $\mathbf{I}: 0$ as well as $0: 0 .{ }^{1}$

Bacon differs from Plato, who considered forms as absolutely abstracted from matter, and not as confined and determined by it, and agrees with Aristotle in saying that words are the images of thoughts ; ${ }^{2}$ so that the agreement of the views of Bacon with those of Prof. Max Muiller would seem to be tolerably close. It is easy to find cases in which a doubtful meaning of a word may give rise to disagreement on matters of substance. Boole (" $\mathrm{L}$. of T.," pp. 407, 408) observes that the term "necessary" may be applied either to the observed constancy of nature or to the logical connection of propositions. He expresses no decided preference for either meaning. The meanings should be kept carefully apart. If an axiom be a necessary truth, in the strictest sense, then Newton's laws of motion are laws a priori, viz. giving Kant's meaning to the term ("Prol.,"p. IO3); they are known independently of all experience. But Laplace ("Méc. Cél.," pp. J4-183) treats them as results of experience. Moreover, he treats (pp. 65-69) the laws of motion under all the relations mathematically possible between force and velocity. Newton, in fact, usually speaks of "law," and gives the term "axiom" Bacon's meaning.

Buo'e's chapter xx. ("L. of T.," pp. 320-75) relates to problems on causes, but his use of the word "cause" has given rise to much discussion. He proposed a question on causes in $185 \mathrm{I}$, which was answered by Prof. Cayley in 1853 . The solution was criticized by Boole in 1854, who arrived at a different result, and in $1854, \mathrm{Mr}$. H. Wilbraham examined both solutions. Prof. Cayley returned to the subject in $\mathbf{I}<62$, and Boole thereupon admitted that it would have been better, in stating his problem, not to have employed the word "cause" at all." One mode of stating the nature of the relation between "cause" and "effect" may be this, viz. when a certain (antecedent) change is immediately and invariably followed by a certain other (subsequent) change, then the relation in which the antecedent stands to the subsequent (which may now be called the consequent) change is that of cause and effect. This is, in su:stance, if not in form, a view common to Algazel, Glanvil, ${ }^{5}$ Hume, ${ }^{6}$ Brown, ${ }^{7} \mathrm{Kant}$, and, as I believe, Reid; for the quesion seems to be one about words. It differs but slightly from the view (C. T., vol. x., part 2, p. 300) of l,e Morgan. Perhaps " unvarying" might be a better word than " invariable," for one instant of time is the immediate and invariable antecedent of its consecutive instant ; but the idea of " cause" does not seem to arise. When "cause" is used in the above sense, the solutions of Boole and Prof. Cayley agree. Boole's question has been dealt with in our Proceedings (vol. xi. p. I 8 ) by $\mathrm{Mr}$. McColl.

The import of the word "principle" is not the same when we speak of the principle of contradiction or of excluded middle, as when we speak of the principle of the permanence of equivalent forms, or of the sufficient reason, or of continuity. That of sufficient reason has been assailed by Brown ("C. and E.,"

I See the last footnote but one.

Bacon, "Advancement of Learning," p. 143 ; conf. pp. хзо, г4o. See also pp. ז92, 209 .

3 My pagings refer to the 2 nd ed. of the "Mécanique Céleste," vol. i. (Paris, 1829 )

4 bo le, C. and D. M. F., vol. vi. p. 286; "L. of T.," pp $3^{2126}$ Phil. Mag., S. 4 , vol. vil. Fp. $29-32$; vol xxiii., pp. $36 \mathrm{r}-63$; Wilbraham, Phil. Mas., S. 4. vol. vii. pp. $465-76$; Cayley, Phil. Mag, S. 4, vol vi p. 259 ; S. 4 , vol. xxiil. pp. $352^{2-65}$, and 470 . A sh rt letter by Bo le (f'hil. Mag., S. 4, vul xxiv. (1862), p. 80, cunculues the discussion.

5 Glanvil (Joseph), "Scepsis Scientifica," \&c. (Lond. I665, 4to) Lond. I885, 8vo." On Causation, 1 have only mentioned comparatively recent authors. But, going further back, we find Thales (with his elemental aralysis), Xenophanes (with his one cosmic substance), and Pythagoras (with his arithmetical and geometrical combinations), all recognizing invariable sequences in nature; and Socrates admitted a class of phenmena wherein the connection of antecedent and consequent was invariable and ascertainable by human study (Grote, "History of Greece," vol, i., 1846 , pp. 495-98). Socrates applied similar scientific reasonings to moral and social phenomena (ib., p. 504 ).

6 Davd Hume, "A Treatise of Human Nature," \&c. (Lond, vols. i. and ii., I739; vol. ili., I740: his name does not appear on the title-pages). "Phil, sophical Essays concerning Human Understanding" (2nd ed. Lond., 1750). "An Inquiry concerning Humais Understanaing" (Lond, I861) marks the issue to which I refer.

marks the issue to which I refer. ed., Fdinburgh, I8I8). Draper does not ad init the construction put upon ed., Edinburgh, 1818). Draper does not adinit the construction put upon facsimile reprint of Glanvil has been published within the last few years. Buckle pronounced Brown's to be one of the best books ever written. sect. iv. pp. 222, mishumbered 322, to 306), and by De Morgan (C. T., x., part 2, pp. 290-304). Clifford (op. cit., p. xl.) was prepared to sacrifice the principle of continuity, even in the case of space, and the author of anonymous "Strictures" on Peacock's "Algebra" (Camb., 1837), who was (so at least I was told many years ago by Davies) Hind, concludes (p. 2I) that number is perfectly abstract, that it is the only thing which is so, that it is not rightly denominated a species of quantity, being equally connected with every species. An instance of a striking failure of the principle of the permanence of equivalent forms is given by Dr. I. W. L. Glaisher in the Messenger of Mathematics, N. S., vol. ii. (1872) p 95. Again, take another word -viz "disparity." Supposing it to be said that there are two persons in a room, whose united ages are twenty-one years, and between whose ages there is the greatest disparity possible. This is intelligible if one be a new-born or nascent infant, and the other a person aged twenty-one. But suppose the same statement made of three persons; the proficient in language might have to inquire of the mathematician what meaning, if any, the statement bears. Or, again, the mathematician might be asked what, or whether any, numerically definite meaning can be attached to the words, "triangle of maximum scalenity."

Prof. Newman ("Logic," 1838 , p. 52) says that the truths of arithmetic are verbal. Perhaps this, and the corresponding statements of Dugald Stewart, would not now be insisted on. They are opposed to the views of Kant, Clifford, and De Morgan (C. T., xi., part I, p. 160). The identities $3^{2}+4^{2}=5^{2}$, and $3^{3}+4^{3}+5^{3}=6^{3}$, seem to be something very different from definitions of words. Kant considers $7+5=12$ to be a synthetical judgment ("Proleg.," pp. 22, 23).

Metaphysics and mathematics are consorts in the East as well as in the We-t. Bhascara says that the analytical art $\mathrm{i}$ - merely sagacity exercised, and is independent of symbols, which do not constitute the art. ${ }^{1}$ If De Morgan ${ }^{2}$ be right in placing Diophantus as late as the beginning of the seventh century, Aryabhatta was earlier, by two centuries, than Diophantus. The name certainly seems to have been a vrry common one. Josephus ${ }^{3}$ relates that Alexander (a son of Herod the Great) said that Diophantus the scribe had imitated his hand. But Mr. Heath's work ${ }^{4}$ renders it scarcely possible to sustain De Morgan's contention.

\section{EXHIBITION OF METEOROLOGICAL INSTRUMENTS.}

THE Royal Meteorological Society's tenth annual Exhibition of Instruments was held in the rooms of the Institution of Civil Engineers, 25 Great George street, Westminster, from the I9th to the 22nd instant. This Society's Exhibitions are always interesting and instructive, as each one is devoted to some special class of instruments : this year the instruments consisted principally of actinometers and solar radiation apparatus. Specimens of most of the various forms of these instruments were exhibited; but when it was not possible to obtain an instrument itself, a photosraph or drawing of it was shown, so that the visitors to the Exhibition could readily see what instruments have actually been made.

Several specimens were exhibited of Sir John Herschel's actinometer, for ascertaining the absolute heating effect of the solar rays, in which time is considered one of the elements of observation. This consists of a large cylindrical thermometer bulh, with a special open scale, so that minute changes may be easily seen. The bulb is of transparent glass filled with a deep blue liquid, which is expanded when the rays of the sun fall on the bulb. When taking an observation, the actinometer is shaded for one minute and read off; it is then exposed for one minute to sunshine, and its indication recorded; it is finally shaded again, and its reading again noted. The mean of the two readings in the shade, subtracted from that in the sun, indicates the expansion of the liquid produced by the sun's rays in one minute of time.

The Kew Committee exhibited Hodgkinson's actinometer, the principle of which is the same as that of Sir J. Herschel's,

Colebroke, "Algebra," \&cc. (London, 1817). p. xix.

3 Josephus, "Antiquities of the Jews" (Burder's Translation, vol. i. pp. $6 \mathbf{r} 6,617)$. Burder's preface is dated Lond in. October $\mathbf{r}, \mathbf{1} 81 \mathrm{r}$

4 T. L. Heath. "Diophantos of Alexandria: a Study in the History of Greek Algebra" (Cambridge University Press, $\mathbf{3}^{8}, 5$ ). 